\title{
A importância da prática de leituras para o desenvolvimento do senso crítico na sala de aula
}

O presente artigo destaca a importância da leitura significativa no cotidiano da sala de aula. O objetivo do trabalho é refletir sobre as habilidades relacionadas à leitura como: compreensão, reflexão e interpretação. Através de métodos novos no ensino e aprendizagem, almeja-se conhecer principalmente o processo de alfabetização, desenvolvendo um diálogo entres vários autores, a fim de contribuir para a melhoria dos índices de qualidade da alfabetização, sugerindo um novo pensamento crítico sobre as abordagens de ensino. Por meio da metodologia qualitativa, com a utilização de observações e revisão bibliográfica, buscou-se a compreensão entre os diferentes autores que incentivam a pratica da leitura e a preparação de leitores críticos. Ao longo desde estudo, foi possível identificar grandes contribuições para a formação de uma cultura que valoriza a leitura entre seus membros, além da valorização da aquisição de linguagens literárias, artísticas e históricas, a partir da compreensão do seu papel enquanto sujeito histórico. Concluir-se que o hábito de leitura tem se perdido não apenas nas escolas, e torna-se necessário que o professor compreenda os diferentes métodos e abordagem pedagógicas para atingir o objetivo de proporcionar aprendizagen significativas para os educandos, através de transformações de conceitos e necessidades que limitem o aprendizado, buscado dessa maneira, o avanço do conhecimento científico sobre o desenvolvimento da leitura na educação e na prática cotidiana.

Palavras-chave: Escola; Leitura; Leitores; Ler; Senso Crítico.

\section{The importance of reading practice for the development of critical sense in the classroom}

\begin{abstract}
This article highlights the importance of meaningful reading in the classroom. The aim of the work is to reflect on reading-related skills such as: understanding reflection, and interpretation. Through new methods in teaching and learning, we aim to learn mainly about the literacy process, developing a dialogue between various authors, in order to contribute to the improvement of literacy quality indexes, suggesting a new critical thinking about teaching approaches. Through the qualitative methodology, with the use of observations and bibliographic review, it was sought the understanding between the different authors that encourage the practice of reading and the preparation of critical readers. Throughout this study, it was possible to identify major contribution to the formation of a culture that values reading among its members, in addition to valuing the acquisition of literary, artistic and historical languages, from the understanding of its role as a historical subject. To conclude that the reading habit has been lost not only in schools, and it is necessary for the teacher to understand the different methods and pedagogical approach to achieve the objective of providing meaningful learning for students, through transformations of concepts and needs that limit the learning, sought in this way, the advancement of scientific knowledge about the development of reading in education and daily practice.
\end{abstract}

Keywords: School; Reading; Readers; Read; Critical sense.

Topic: Práticas, Didática e Metodologias do Ensino

Reviewed anonymously in the process of blind peer
Received: $\mathbf{2 4 / 1 0 / 2 0 2 0}$

Approved: 25/01/2021
Neidiara da Silva Feitosa (iD

Universidade Norte do Paraná, Brasil

http://lattes.cnpq.br/8056138395761376

http://orcid.org/0000-0003-3426-3004

yara.feitosa48@gmail.com

Francenilde da Silva Feitosa (iD

Universidade Norte do Paraná, Brasil

http://lattes.cnpq.br/6244322090047487

http://orcid.org/0000-0002-3779-6490

francenilde19@gmail.com

Francisco Rubens Feitosa Júnior (id

Universidade Federal do Sul da Bahia, Brasil

http://lattes.cnpq.br/1603533849627421

http://orcid.org/0000-0001-7793-2138

rubensjr21@hotmail.com

\section{Referencing this:}

FEITOSA, N. S.; FEITOSA, F. S.; FEITOSA JÚNIOR, F. R.. A importância da prática de leituras para o desenvolvimento do senso crítico na sala de aula. Educationis, v.9, n.1, p.46-52, 2021. DOI:

http://doi.org/10.6008/CBPC2318-3047.2021.001.0006

DOI: 10.6008/CBPC2318-3047.2021.001.0006 


\section{INTRODUÇÃO}

A alfabetização acontece quando linguisticamente ocorre o domínio do conhecimento que permite ao indivíduo a codificação e decodificação do código alfabético. Sintetizando alfabetizar é instruir um indivíduo a se apropriar do código escrito. Em decorrência dessa finalidade o indivíduo para aprender a ler e escrever precisa interagir e se apropriar das letras e sons as quais as mesmas podem formar, codificar ou decodificar (KOCH et al., 1989; TRAVAGLIA, 1996; TRAVAGLIA, 2010).

Para se alcançar a alfabetização a leitura é uma das principais ferramentas utilizadas em sala de aula, porém não é um instrumento apenas de alfabetização, pois o indivíduo que se apropria das técnicas de leitura, torna-se um ser crítico, capazes de resolver desafios sociais que existem em seu cotidiano (ALMEIDA JÚNIOR, 2009). A leitura permite que o indivíduo interaja com outras realidades, que sua imaginação se torne mais fértil, sendo assim mais fácil a sua capacidade de absorver novos conhecimentos e gerar também reflexões sobre sua realidade (FREIRE, 2011).

Nesse sentido, a importância da leitura e do caráter polissêmico da literatura são elementos essenciais na formação dos educandos, pois, a leitura promover ampliação do indivíduo no contexto sócio educativo, porque é um processo continuo que auxilia o indivíduo para que seja capaz de gerar novas chaves de interpretação de textos diversos, contribuindo para a construção do conhecimento e geração de novas formas de conhecimento (MARTINS, 1988; FREIRE, 2011).

O conceito de literatura envolver uma subjetividade temporal, e configurada na inerente capacidade multifacetada e polissêmica (ABREU, 2006; LAJOLO, 1982), o que significa que a literatura possui amplitude de significados e significação da linguagem que se modifica de acordo com o contexto social onde está inserida. Na prática cotidiana a leitura é um tema agradável, no qual se pode aprender e também modificar a sociedade, colaborando para o desenvolvimento de indivíduos capazes de valorizar sua cultura, diminuir preconceitos e trazer soluções para conflitos sociais existentes (HUNT, 2010; ORLANDI, 1998).

A leitura significa na prática cotidiana dessa maneira, um instrumento fundamental, insubstituível para o sucesso dos educandos e educadores em sala de aula. Tendo em mente que a quantidade de indivíduos que saem do ensino fundamental sem interpretar o que leu ainda é uma realidade que precisa ser avaliada para ser possível extinguir esse problema (COSSON, 2014).

Dessa forma o presente estudo analisa a qualidade do ensino no processo de aquisição da leitura. Trazendo à baila as seguintes perguntas: Qual a maneira adequada da pratica da leitura? Como incentivar os educandos a praticar leituras cotidianas? Qual o papel da escola como formadora de leitores críticos?

Com isso, se verificou que para compreender o processo da aplicação da leitura como técnica fundamental para o bom desenvolvimento da criança e do adolescente, cabe aos profissionais docentes empregar a leitura em suas aulas considerando como aspecto de integração e socialização, baseada em uma pratica pedagógica centrada na leitura e interpretação de textos didáticos. 


\section{METODOLOGIA}

O presente trabalho se constitui de uma pesquisa qualitativa por meio de uma pesquisa bibliográfica, que procurou analisar entre teóricos e críticos as principais abordagem e práticas utilizadas no campo educacional para valorização da leitura e formação de um sujeito crítico e conhecedor de sua realidade cotidiana. Desta forma a revisão bibliográfica foi realizada conforme Lakatos et al. (2005).

A análise de conteúdo bibliográfico foi feita segundo Bardin (2011), com leituras e anotações sistematizadas referentes ao foco do estudo, por meio de uma síntese de fontes secundárias publicadas em jornais, revistas, livros, monografias, artigos, dissertações, teses e outros.

Com o intuito de obter uma concepção fundamentada sobre o estado atual dos conhecimentos a respeito da problemática da pesquisa. Posteriormente realizou-se a leitura dos resumos para identificar ações referentes a alfabetização implementadas em Instituições Escolares. Por último se realizou uma pesquisa documental sendo utilizada para identificar os principais avanços nos últimos anos.

\section{Como ocorre o processo de codificação e decodificação na atividade de leitura}

Ler é conhecer o significado das palavras lidas, interpretar e descobrir a realidade que o autor deseja passar aos seus leitores. A ideia de decodificação dos signos ultrapassa o campo da área de letras e pedagogia e se presentificar no mundo, é nesse sentido que a leitura crítica da realidade possibilita o processo de alfabetização constituindo-se num instrumento para o que Gramsci chamaria de ação contra hegemônica (FREIRE, 1990).

A leitura significa ir além do reconhecer das letras do alfabeto (MARTINS, 1988), e é o ato de decifração dos símbolos e do conhecimento no contexto onde o texto está inserido como nos afirmam Dering et al. (2017). Dessa forma, a leitura proporcionará o maior vocabulário e adicionará conhecimento ao leitor (DERING et al., 2017; FERREIRA et al., 2002; FREIRE, 2015).

Ler é entender o sentido anexado em cada um dos símbolos descodificados, é mapear a significância atribuída pelo autor da narrativa e confrontar experiências e vivencias suas com as descritas no texto, encontrando dessa forma, uma maneira que induz o leitor a questionar e a buscar suas próprias respostas tornando-se um sujeito reflexivo e crítico da sua própria realidade (FREIRE, 1990).

Quando essa visão de leitura conforme Freire (1990) se faz presente na sala de aula o educando está em um ambiente propicio para geração de conhecimento de qualidade, porém quando essa visão não está presente o lugar não colabora para seu aprendizado, e o leitor não se torna um sujeito ativo que tenha capacidade de entender textos e absorver conhecimentos, experiências e esquemas prévios (SOLÉ, 1998).

O sujeito leitor tem uma imaginação estimulada por seus constantes atos de decodificação, e necessita de um treinamento mental significativo que promova ao mesmo tempo a capacidade reflexiva que o distanciará do analfabetismo funcional, e capacitará o mesmo para maiores oportunidades de trabalhos e desenvolvimento profissional, por isso precisa de uma sala de aula dinâmica e propicia ao seu aprendizado (MOSÉ, 2013). 
Dessa forma a leitura ou o ato de ler, acontece principalmente na infância em salas de aulas, através da função do professor como agente educador que está a inserir o indivíduo nas mais variadas atividades literárias (MARTINS, 1988), porém ressaltar-se a importância social que todos os indivíduos têm de auto estimular-se a pratica de leitura diárias em suas próprias realidades durante o percurso de sua vida.

\section{DISCUSSÃO TEÓRICA}

\section{A valorização da leitura cotidiana}

$\mathrm{O}$ ato de ler permite principalmente a criança e adolescente em sala de aula uma atividade lúdica que acrescenta novos significados sociais a realidade dos educandos, e a prática de leitura deve se basear de forma gradativa e substancialmente construída e adaptada as necessidades do estudante e não vincular isso a um roteiro que comprometa o aprendizado e o estimulo a leitura em decorrência de uma programação, a qual eles não se adaptem ou não se sintam estimulados (SOLÉ, 1998; BAKHTIN, 1997; COSSON, 2014).

Dessa forma esse processo deve acontecer o mais atrativo possível, para que seja possível estimular ao máximo a visão reflexiva e crítica dos novos leitores, ao mesmo tempo que desperta neles o afeto pela atividade da pratica constante da leitura, para que mesmo sozinhos tenham o hábito contínuo de executar essa função (BRASIL, 1998; MARQUES, 2003; VIANA, 1999). A leitura dessa forma deve aumentar a aptidão intelectual do indivíduo que desenvolvendo a criatividade e a sua relação com o meio externo terá maior conhecimento sobre sua realidade (MORAN, 1997).

O indivíduo que realiza uma leitura ativa está pronto a desenvolver novas habilidades, ao contrário de outros que não possuem contato com esse universo e se distanciam desse ingresso constante no processo de crescimento e aprendizado (VIGOTSK, 2001). Dessa forma sempre estará conhecendo novas palavras o educando leitor, frases ou expressões, que possibilitará a compreender os mais variados assuntos, de modo a refletir e gerar novos significados (MARCUSCHI, 2008).

O procedimento de leitura e escrita acontece na escolarização, porém a criança no âmbito familiar e em seu convívio social necessita de estímulos pelo ato de ler e de escrever para que o processo aconteça de forma eficiente e a criança consiga os requisitos básicos de compreensão e escrita textual (FREIRE, 1990; VIANA, 1999).

É importante ressaltar que as crianças são inseridas no meio escolar sem compreender incialmente qual o seu papel na escola e o papel do professor em suas vidas, tendo apenas em mente o convivo obrigatório com outras crianças e professores, a qual a escolha é feita por seus responsáveis, onde tudo é planejado e organizado pelos adultos (DAYRELL et al., 2016; SILVEIRA, 2013). Desse modo é necessário que os responsáveis e professores tenham maior paciência e cuidado para se fazer entender inicialmente qual é a proposta de ensino para que esses jovens educandos venham se sentir motivados a aprender (FERREIRA et al., 2018; SILVA, 2018).

Inicialmente a leitura, acontece por meio de instruções ministradas pelo professor e o aluno tem a incumbência de adaptar-se as exigências e os processos de trabalho que lhe são impostos pelo educador 
(BOVA et al., 2018; BANKS-LEITE, 1996; VIGOTSKI, 2009). Isto pode ocasionar uma desmotivação, que deve ser evitada através de uma leitura criativa que busque inseri-los no mundo da leitura e da escrita por meio de abordagem que seja adequada para cada necessidade dos educandos (BAKHTIN, 2012; KLEIMAN, 1995; VALSINER, 2017).

É através da leitura cotidiana que eles serão bons leitores e podem confrontar com opiniões diversas de amigos e colegas, e desenvolver o seu próprio raciocínio, além da geração de valores para as coisas que fazem parte da sua vida social e afetiva (PILETTI, 2010). Agregando conceitos sobre sua realidade, nacionalidade, cultura e até mesmo entendo comportamentos que são praticados pela sua família e entes queridos (FERRARI, 2008).

Os contatos iniciais da criança com a leitura são fundamentais para construção das suas percepções, pois relaciona-se à formação do ser humano crítico, capacitado a encontrar resoluções para os desafios que possam aparecer em sua vida. Uma vez que a leitura faz parte da vida da criança ela se torna capaz de decifrada e trabalhada com volumes maiores e mais aprofundados de textos, porque já dispõe de estrutura de compreensão que antes não possuía (MORAN, 1997)

Dessa forma o conhecimento da realidade é importância para ato de ler, pois se expressa no cotidiano de cada indivíduo, que através disso dispõe de maior racionalidade e capacidade de interpretação (VIGOTSKI, 2009). Assim, a prática cotidiana da leitura significativa efetiva participação social que transforma a vida das pessoas através da experiência do ato de ler.

\section{Educação escolar através da motivação do ato de ler}

A educação desperta no indivíduo a sensibilidade para entender as transformações que ocorre ao seu redor, criando um sujeito ativo que visualiza a leitura, como um dos seus eixos de desenvolvimento principais de sua vida, pois é capaz de adquiri novos conhecimentos e percebe-se o mundo ao seu redor pelo ato de ler (SOARES, 1998).

Dessa forma as práticas pedagógicas são fundamentais e a escola deve dar prioridade a atividades e projetos relacionados à leitura para que a metodologia de ensino tome sempre novos rumos, se tornando cada vez mais dinâmica. Ampliando a visão do educador que também aprende dessa forma com o educando e se preocupa se houve ou não o real aprendizado, aquele que possibilitar ao estudante o senso crítico do assunto trabalhado (MONTESSORI, 1965).

A escola possui um papel importante na formação de leitores, e deve sempre deixar em evidencia que a leitura de textos, seguidos por cópias e exercícios dirigidos são exercícios para reflexão e compreensão de relevante importância. Desse modo, é necessário que o professor busque situações onde o aluno realize leituras, concordando ou discordando do que foi apresentado (VIANA, 1999).

A leitura representa uma das boas vias para entender a realidade, porém deve-se evitar mecanizar esse processo, buscando sempre resumir as principais ideias que o texto pretende transmitir e efetuar reflexões acerca das ideias principais. Para se alcançar o entendimento do texto, a crítica com base em pressupostos pode ajudar a descobri chaves de interpretação do texto, e isso operações mentais mais 
complexas do que a simples recepção de informação (BAKHTIN, 1997; COSSON, 2014).

O conhecimento é uma construção baseado em práticas pedagógicas que deve ser constantemente assista pelo professor, e os resultados obtidos junto aos seus grupos de estudantes, em um determinado contexto escolar e no decorrer do tempo, deve ser analisado constantemente (VIGOTSKI, 2009). Dessa forma se compreende o professor como agente fundamental no processo ensino e aprendizagem, e para que o educando possa saiba ler criticamente, o professor deve organizar programas pedagógicos que permitam o diálogo e interação com seus alunos.

\section{CONCLUSÕES}

O ambiente escolar é fundamental na pratica da leitura e formação do leitor, pois é um espaço com essa finalidade especifica, e dispõe de profissionais capacitados que tem total condição de proporcionar uma abordagem pedagógica satisfatória para que seja possível se atingir melhores índices alfabetização através da leitura.

Dessa forma, torna-se necessário que o professor compreenda os diferentes métodos e abordagem pedagógicos para atingir o objetivo de proporcionar aprendizagens significativas para os educandos, através de transformações de conceitos e necessidades que limitem o aprendizado, buscado dessa maneira, o avanço do conhecimento científico sobre o desenvolvimento da leitura na educação e na prática cotidiana.

No contexto escolar a vivência de uma abordagem pedagógica que considere a aprendizagem através dos conhecimentos acumulados historicamente pelas produções culturais e artísticas possibilita ao educando uma melhor formação para que tenham um desenvolvimento satisfatório. Com isso, se verificou que para compreender o processo da aplicação da leitura como técnica fundamental para o bom desenvolvimento da criança e do adolescente, cabe aos profissionais docentes empregar a leitura em suas aulas considerando como aspecto de integração e socialização, baseada em uma pratica pedagógica centrada na leitura e interpretação de textos didáticos.

\section{REFERÊNCIAS}

ABREU, M. A.. Cultura Letrada, literatura e leitura. São Paulo: UNESP, 2006.

ALMEIDA JÚNIOR, O. F.. Mediação da Informação e Múltiplas Linguagens. Tendências da Pesquisa Brasileira em Ciência da Informação, Brasília, v.2, p.89-103, 2009.

BAKHTIN, M.. Estética da Criação Verbal. 2 ed. São Paulo: Martins Fontes, 1997.

BAKHTIN, M.. Estética da criação verbal. São Paulo: Martins Fontes, 2012.

BANKS-LEITE, L.. Aspectos argumentativos e polifônicos da linguagem da criança em idade pré-escolar. Tese (Doutorado) - Universidade de Campinas, Campinas, 1996.

BARDIN, L.. Análise de conteúdo. São Paulo: Edições 70, 2011.
BOVA, A; ARCIDIACONO, F.. Types of conclusion for argumentative discussions between adults and children. Progress in Education, 53, 135-160, 2018.

BRASIL. Parâmetros Curriculares Nacionais do Ensino Médio. Brasília: MEC; SEMTEC, 1998.

COSSON, R.. Círculos de leitura e letramento literário. São Paulo: Contexto, 2014.

DAYRELL, J. T.; JESUS, R. E.. Juventude, ensino médio e os processos de exclusão escolar. Educação \& Sociedade, Campinas, v.37, n.135, p.407-423, 2016. DOI: https://doi.org/10.1590/ES0101-73302016151533

DERING, R. O.; SILVA, E.. Cinco (im)possiblidades para a formação de leitores no ambiente escolar público. Revista Água Viva, v.2, n.1, 2017.

FERRARI, M.. Emília Ferreiro, a estudiosa que revolucionou 
a alfabetização. 2008 .

FERREIRA, R. A.; RAMOS, L. O. L.. O projeto da MP no 746: entre o discurso e o percurso de um novo ensino médio. Ensaio: Avaliação e Políticas Públicas em Educação, Rio de Janeiro, v.26, n.101, p.1176-1196, 2018. DOI: https://doi.org/10.1590/s0104-40362018002601295

FERREIRA, S. P. A.; DIAS, M. G. B. B.. A escola e o ensino da leitura. Psicologia em Estudo, v.7, n.1, p.39-49, 2002.

FREIRE, P.. A importância do ato de ler: em três artigos que se completam. 51 ed. São Paulo: Cortez, 2011.

FREIRE, P.. A importância do ato de ler: em três artigos que se completam. São Paulo: Cortez, 1990.

FREIRE, P.. Pedagogia do Oprimido. Rio de Janeiro: Paz e Terra, 2015.

HUNT, P.. Crítica, teoria e literatura infantil. São Paulo: Cosacnaify, 2010.

KLEIMAN, Â.. Os significados do letramento. Campinas: Mercado das letras, 1995.

KOCH, I. G. V.; TRAVAGLIA, L. C.. A coerência textual. São Paulo: Contexto, 1989.

LAJOLO, M.. O que é literatura. São Paulo: Brasiliense, 1982.

LAKATOS, E. M.; MARCONI, M. A.. Fundamentos da metodologia cientifica. São Paulo: Atlas, 2005.

MARCUSCHI, L. A.. Produção textual, análise de gêneros e compreensão. São Paulo: Parábola, 2008.

MARQUES, M. O.. Escrever é preciso: o princípio da pesquisa. Ijuí: Unijuí, 2003.

MARTINS, M. H.. O que é leitura? São Paulo: Brasiliense, 1988.

MONTESSORI, M.. Pedagogia científica. São Paulo. Livros para o Progresso, 1965.

MORAN, J. M.. Como utilizar a Internet na educação. Ciência e Informação, Brasília, v.26, n.2, 1997.

MOSÉ, V.. A escola e os desafios contemporâneos. Rio de Janeiro: Civilização Brasileira, 2013.

ORLANDI, E. P.. A polissemia da noção de leitura. Discurso e leitura. São Paulo: Cortez, 1998.

PILETTI, N.. Educação Básica: da organização legal ao cotidiano escolar. São Paulo: Ática, 2010.

SILVA, M. R.. A BNCC da reforma do ensino médio: o resgate de um empoeirado discurso. Educação em Revista, Belo Horizonte, v.34, p.214-130, 2018. DOI: https://doi.org/10.1590/0102-4698214130

SILVEIRA, A. D.. Conflitos e consensos na exigibilidade judicial do direito à educação básica. Educação \& Sociedade, Campinas, v.34, p.371-387, 2013. DOI:

https://doi.org/10.1590/S0101-73302013000200003

SOARES, M.. Letramento: um tema em três gêneros. Belo Horizonte, 1998.

SOLÉ, I.. Estratégias de leitura. Porto Alegre: Artmed, 1998.

TRAVAGLIA, L. C.. Gramática e interação: uma proposta para o ensino de gramática. São Paulo: Cortez, 1996.

TRAVAGLIA, L. Que análise linguística operacionalizar no ensino de Língua Portuguesa?. In: TAGLIANI, D.; SILVA, E. N.; OLIONI, R. C.; FEIJÓ, R. N.. O ensino de Língua Portuguesa no séc. XXI: desafios e possibilidades. In: SEMINÁRIO NACIONAL SOBRE LINGUÍSTICA E ENSINO DE LÍNGUA PORTUGUESA, 2. Anais. Rio Grande: FURG, 2010

VALSINER, J.. Fundamentos da Psicologia Cultural. Mundos da mente, mundos da vida. Porto Alegre: Artmed, 2017.

VIANA, A. C.. Roteiro de redação: lendo e argumentando. São Paulo: Scipione, 1999.

VIGOTSKI, L. S.. Psicologia pedagógica. Porto Alegre: Artmed, 2001.

VIGOTSKI, L.. Construção do Pensamento e da Linguagem. São Paulo: Martins Fontes, 2009.

A CBPC - Companhia Brasileira de Produção Científica (CNPJ: 11.221.422/0001-03) detém os direitos materiais desta publicação. Os direitos referem-se à publicação do trabalho em qualquer parte do mundo, incluindo os direitos às renovações, expansões e disseminaçães da contribuição, bem como outros direitos subsidiários. Todos os trabalhos publicados eletronicamente poderão posteriormente ser publicados em coletâneas impressas sob coordenação da Sustenere Publishing, da Companhia Brasileira de Produção Científica e seus parceiros autorizados. Os (as) autores (as) preservam os direitos autorais, mas não têm permissão para a publicação da contribuição em outro meio, impresso ou digital, em português ou em tradução. 